\title{
Adapted consumption schemas: Reflections on the dynamic relationship between consumers and marketed goods.
}

\author{
Vargas-Bianchi, L. \\ Instituto de Investigación Científica, Universidad de Lima \\ Ivargas@ulima.edu.pe (corresponding author) \\ Orcid: 0000-0002-9027-7673
}

Citation:

Vargas-Bianchi, L. (2020). Adapted Consumer Schemas: Reflections on the dynamic relationship between consumers and marketed goods. SocArxiv https://doi.org/10.31235/osf.io/as23h

\begin{abstract}
This essay elaborates about the dynamic relationship between consumers and products, taking in account well-being as an expected outcome, and the subjective manner in which individuals process information. Several concepts are taken in account: cognitive schemas, prior studies made on well-being and hedonic utility. The essay proposes a conceptual frame entitled adapted consumption schemas, to construe the projected expectation of satisfaction by the consumer, consistent with his beliefs and values system in a given moment.
\end{abstract}

Key words: consumer behavior, consumption, forecasted utility, purchase satisfaction

\section{Introduction}

Wellbeing is understood in several ways. When people today use the word, they do in association with a sense of positive emotion or affection. It is also common to use it as an abbreviated form to refer to the person's satisfaction with aspects of his or her life. A term that also approaches such a sense is joy, however the latter is sometimes regarded as a more intangible reality because it is a more existential personal state of experience. Over the years the western-world concept of well-being has been broadly studied, and as a result it has been attributed to multiple meanings, some different from those described. In the Christian perspective, well-being is linked to a state of blessing related with the experience of happiness, where the believer expects an even greater good in a future life. Thus, in Christianity well-being is not related to pain, as in philosophical views that will be exposed later. In the Aristotelian tradition, the word eudaimonia is used to describe happiness as the vital goal of every subject, even if the subject is not aware of it. The philosopher proposed that this state is reached through the experience of a good life through virtuous action, cultivated by habit or repetition, dynamics by which the person achieves his fullness. However, his concept comes closer to that of happiness than well-being, which is the point on which this essay is about. Centuries later, during the Enlightenment, positive affection or emotion and pleasure were raised as individual values sustained in themselves, achieving to some extent the category of fundamental rights. It could be said that it was around the ideas of this time that the foundations 
were laid for the construction of social architecture that allowed each individual to seek individual satisfaction or well-being in the modern sense with which we now use the term more widely.

This more often overlaps the sense of well-being with hedonism and the experiences associated with the hedonic in its sense of pleasurableness, in a dimension like that posed by the utilitarian perspective of the philosopher J. Bentham. However, well-being and hedonism do not seem to be synonymous, while the former has characteristics typical of a practice or attitude to the vital, the latter is linked to the search for pleasure. Utilitarian hedonism has the characteristic of being prone to dynamic adaptation of the person with their environment. Over time the individual needs a greater amount and intensity of stimuli to feel the same level of pleasure you experienced with an event. This phenomenon is called 'hedonic stability', where pleasure experienced is measured in relation to the previous hedonic states, so that at each new opportunity the individual needs more intense stimuli to maintain the degree of hedonism he seeks to experience.

There are several theories that explain well-being and its attainment. Needs-based theories, which will be explained later in the document, expose inventories of elements that individuals need to satisfy to achieve well-being. Other more elaborate theories are presented that exceed the momentary satisfaction of a satisfied need, such as the so-called PERMA (by the initials of pleasure, engagement, relationships, meaning, accomplishments) developed by the psychologist Seligman (2011). This and other positions around satisfaction stem from the realm of positive psychologya school proposed by the latter author - that to understand the well-being of the person incorporate elements such as positive emotions, commitment, relationships with other individuals, the vision he has of himself and his environment, the meaning that life has for the subject and the goals he achieves.

While this essay covers the concept of well-being in the individual, its final orientation points to consumer psychology and marketing, i.e. seeking to understand what stands on well-being have developed in terms of satisfaction linked to consumption of consumer goods. The endeavor is structured in three topics: (i) the schemas as elements of cognitive effort and their role in the organization of data that allows consumer decision-making; (ii) the development of the concept of well-being, its senses and connotations, and (iii) the proposal of a theoretical framework entitled 'Adapted Consumption Schemas'. This work aims to elaborate on these concepts and present a proposal of this framework on the relationship of individuals with products and the well-being that is obtained from them.

\section{Schemas}

The concept of 'schema' seems to be one of the main theoretic elements used by researchers dedicated to observing how thought structures are linked and involved in human behavior (Pace, 1988). Cognitive scientists and therapists have paid greater attention to schemas, elements that hypothesis-based play a key role in mental processes and in the basis of various long-term psychic problems (Padesky, 1994). Rummelhart (1980), a psychologist interested in information processing and human semantics, argued that subjects' breakdown information into generalized fragments that are stored in category form. The author postulated that the schemas were the final 
product of the elaboration of cognitive categories, the same that allow the individual to organize what he learns.

In this way, according to the psychologist, the schemas are organized mental structures that allow the person to capture, understand and associate that information that is being presented to him. The author defined schemas as the 'bricks' of thought or cognition processes. According to the same author, when a subject develops a new knowledge, it is encoded in a pre-existing schema or else organized under a new code (script). In this way it links the concept of schema with the learning dynamics and the functioning of memory, because coding in categories facilitates the subsequent remembrance of knowledge. In a similar sense, Pace (1988) argues that schemas are derived from experiences and learning that arises from them. According to this author, the schemas originate and operate by organizing the continuous accumulation of experiences of each subject into patterns of meaning, which have a subjective character. In this way it makes sense for Pace (1988) to call schemas 'fundamental cognitive structures', as Rummelhart (1980) the titled categorized fragments or categories of knowledge.

While there is not much literature to be about the construct 'schema', the term is used in cognitive psychology and related fields (such as information processing, learning, artificial intelligence). However, the various studies where this concept is used warns that the schema is understood as a cognitive framework whose function is to organize and interpret information, facilitating the mental processes of the person (Paas, et al., 2003; Sheppard and Teasdale, 2000). Thus, a definition that seems appropriate is that offered by Schmidt et al. (1995), who postulate that a schema is the basic structure of components of cognitive organization through which people identify, interpret, categorize and test their experiences. There is also another common aspect in studies on schemas. The concept stands on two dimensions: on the one hand the fact that the schematics have structural properties, the information is organized in a schematic order; the schemas contain propositional elements, i.e. a sense and informational content that points towards something, a schema that denies or affirms a reality (Dozois and Beck, 2008).

Most likely it was the renowned psychiatrist and researcher Aaron T. Beck who bestowed and maintained the relevance of the term 'schema' in the framework of knowledge and studies in psychology, as he introduced him to this field in the mid-20th century. Beck uses the term in a sense that does not stray from the other authors mentioned above, although it is not to be overlooked that he uses it from the perspective of his interests in clinical and therapeutic psychology. In his first book, Beck (1967; Beck and Alford, 2009) gives credit for giving the original meaning to the term schema to describe cognitive or thought structures to the renowned psychologist Piaget (1948). However, Beck added a particular angle to the term, arguing that a schema is the structure that allows filtering and coding the stimuli of the environment, so that people can disaggregate them and organize them again into facets of a psychological order. According to this ideas the schemas allow the individual to categorize and interpret their experiences so they take on meaning. Beck retorted this meaning of the term in later works, where he defines the schemas as 'stable cognitive patterns' that offer the individual a basis for filtering differences and codify the stimuli he faces. In this way, the schemas function as cognitive 
structures, and specific, that govern the processing of information and the behavior of the subject (Beck et al., 1979; Beck and Alford, 2009).

As explained, Beck used the concept of schema as part of his proposal for cognitive behavioral psychological therapy. It is based on a theoretical framework of information processing where schemas become very important (Dozois and Beck, 2008), and where they occur as a normal part of a person's cognitive development (Padesky, 1994). According to their position, we group experiences into categories that allow us to understand and organize the world. Thus, a child groups dogs, cats and lions as 'animals', however it may have a more specific 'pet' schema that includes the first two animals but not the third. The emphasis of Beck's work and collaborators on observing dysfunctional beliefs is one component that distinguishes his cognitive theory from other theories regarding personality disorders. Later the author deepens the relationship between negative cognitive schemas and their relationship with affective states and behavior (Beck and Alford, 2009). This should allow the therapist to identify cognitive structures, or fundamental belief systems, that underlie the misconduct of individuals in whom psychological pathologies are observed. These schemas are changed and thus the individual overcomes maladaptive behavior (Beck and Alford, 2009; Beck et al., 2001, Beck, et al., 1990).

While this perspective belongs to a field of interest outside this treatise, it suggests that cognitive schemas can be adjusted. These have a dynamic nature or some plasticity, so they are subject to modeling by different factors (Beck and Alford, 2009; Beck, et al., 1990; Padesky, 1994). And because his work addressed the concept of schema from a psychotherapeutic perspective, the researcher noted that just as people applied these cognitive frameworks to achieve structured knowledge that would allow them to organize and interpret the surrounding information, they also applied cognitive frameworks on themselves. The subject observes itself and is understood according to his own belief system. Thus, Beck postulated that each person has an outline of himself and others and about the world around them (Beck, 1967; Beck and Alford, 2009; Newman, 2005). The author and colleagues (Beck and Alford, 2009) postulated that each person's schema develops on whether it comprises three dimensions: (i) the image she has of herself, (ii) her perception of the environment, and (iii) her projection of the future. This set was called 'cognitive triad'. It is worth noting that the cognitive triad comprises the idea that a complex reality like the person may require a construct composed of various elements. In this way, it is possible to notice differences between more or less complex schemas according to the number of dimensions covered and their degrees of abstraction - sometimes such as the aforementioned it seems reasonable to refer to multidimensional cognitive schemas. In turn, the theory of cognitive schemas (Pace, 1988) assumes that when subjects gain new knowledge, or face the modification of a knowledge or thought, they seek to make it fit into pre-existing structures in their memory, so that knowledge makes sense. This stance is consistent with the theory of cognitive dissonance stipulated years ago by Festinger (1962), as well as with the tendency to confirm the sessgo of human thought (Jonas et al., 2001).

It may be argued that this is the case stated previously, that the schemas were the final product of the elaboration of knowledge categories, which allow the individual to organize what he has learned (Ruhart, 1980, Paas, et al., 2003; Sheppard and Teasdale, 2000). Or, as Pace argues (1988), 
schemas are a elaboration of patterns of meaning of a subjective nature, originating in the experiences of each individual. In this way, it seems inherent to the schema to always have a subjective origin and content. At this subjective level, and regarding the schema applied to the person (i.e. Beck's cognitive triad), one might wonder what is elaborated earlier: whether the schema and then according to it the organization of cognitions, or whether first happens the learning on which the schemas are elaborated. However, this discussion would have a circular character, since a schema is both a cognition and a cognitive organization. In this way the schemas must operate in both directions, as patterns of learning organization that are elaborated based on the experience of the subject. Even more so when you consider the dynamic nature or plasticity of the concept, as Beck observed (Beck and Alford, 2009; Beck, et al., 1990; Padesky, 1994), a principle from which the new experiences received that are organized according to the schemas of the individual, can modify them.

\section{The sense of 'wellbeing' and 'consumption states'}

Well-being us commonly understood as a mental or affective state of satisfaction, characterized by positive or pleasant emotions that include momentary joy or stable joy. It defers from satisfaction, as this concept refers to the action attending personal needs, to unload the tension that caused by this needs. Satisfaction also depends to the cognitive schema of each individual. Depending on your organization of experiences, and the consequent vision of yourself and your environment, a person may give a particular assessment to a desire or need while another person may carry a value other than (greater or lesser) to that same need when confronted to satisfy it.

Throughout history different philosophers and religious doctrines have identified man's predisposition toward the experience of well-being, suggesting that various characteristics such as love, wisdom, or detachment are cardinal elements of that state. However, utilitarian thinkers like Bentham have postulated that pleasure and the absence of pain are the defining characteristics of a fulfilling life. This explains why members of this line of thought have pioneered studying subjective well-being (SWB), observing the pleasures and pains in their mental, emotional and physical variants that people experience (see Diener, 2009). At the beginning of the twentieth century, the first empirical studies identified and measure subjective well-being., simple questionnaires were used asking interviewees to report their happiness levels by scoring them in closed nominal ranges. Over time, the studies were identifying important characteristics about the experienced well-being. For example, towards the end of the 1960s it was observed that negative and positive affections are independent of each other and not just opposing emotions. This identification allowed them to be studied in subsequent investigations to obtain a more complete overview of the individual's experience. Towards the last decades of the last century studies at SWB increased, so that this field took on a remarkable body of knowledge. Diener et. To. (1999) published a review of the literature of the research on this subject; the renowned cognitive psychologist D. Kahneman had also made contributions in this area due to his interest in psychology and hedonic utility (Kahneman et al., 2003).

Diener (2009) suggests that interest in studying SWB has increased because the population the western countries have reached a level of material abundance and physical health that allows them to think beyond mere survival or attention to basic needs in the short term, setting their 
interest in living experienced satisfaction or subsequent fullness of economic prosperity. The author calls this stage of some societies 'postmaterialist'. It also suggests that SWB takes an interest in its correlation with individualistic thinking trends, where the individual has been interested to define and achieve his own affections and well-being. In this way, SWB corresponds well to the zeitgeist that characterizes Western thought.

The SWB construct does not appear to be a fixed element, but dynamic and multiform. Researchers have observed that according to the forms of thought and culture to which each person belongs, the elaboration of their perception of well-being may vary, i.e. they are not stored static values that are stated when required. Instead, it is noted that people tend to use recent and notorious information from their own experiences to make judgments about their degree of satisfaction. In turn, this effect of anchoring to a data varies in intensity between individuals.

Thus stated, estimates of the SWB, the perception of satisfaction, as much as the report of one's affections over time tend to be influenced by the person's current mood, their beliefs regarding well-being and happiness, as well as their ease of recalling negative or positive information.

After his studies and literature review, Diener (2009; Diener et. To. 1999) has classified the various theories on satisfaction into three large groups, of the common characteristics found in them. These groups are: (i) theories of satisfaction of needs, (ii) theories of activity or processes, (iii) genetic theories and personality predisposition. In the first group (needs satisfaction) it frames those approaches focused on the idea that reducing tensions is the main route that leads to subjective well-being. For example, by reducing pain or by caring for physical needs. In short, it refers to the psychological state of homeostasis (Maslow, 1959), which can be understood from a Freudian perspective or from the humanist psychology proposed by Maslow, both different in terms of his understanding of the motivational dynamics of the person and yet similar in terms of the principle of decreased tension experienced to achieve a balance.

A common criticism of Maslow for his explanation of human motivation is to point out that his model is hierarchical, i.e. postulating that one category of needs must be addressed before he can attend to the next one. This criticism is unfounded because the psychologist himself stated in his original essay that it is unnecessary to follow sequentially the satisfaction of needs, stating that the needs are a dynamic reality and that his model aims to systematize them but not reduce the complexity of the person to it. A mistake is likely to arise from using the term 'hierarchical' when referring to the dynamics of the model of needs and motivations, as this term seems to require a linear sequential process. Neither does the fact that its model is plotted in the form of a pyramid help to do so, because again it seems to have a special impact on the hierarchy, because in the triangular shape of the pyramid a direction or sequence is noted. More current studies have observed a correlation between needs satisfaction and SWB status. They explain that the person perceives greater well-being when they are closest to the vital goals or standards that arise.

Other authors, who make up the second group of theories (linked to activity or processes) have identified that engaging in activities that satisfy the person or move towards goals that the person proposes are elements related to the level of well-being that the person experiences. One of the first proponents of this perspective was Csikszentmihalyi $(1975,1999)$. The psychologist posits 
that people are more satisfied when they engage in activities that interest them and harmonize with their skill levels. Csikszentmihalyi calls the mental state that originates from this experience as 'flow'. Other research has also found relationships between interesting actions where enjoyment and well-being occur that people report when they are in that circumstance.

Other authors argue that there are elements of stability that make up in SWB that are not explainable from stability in subjective well-being of the individual, because circumstances can change, and it is observed that some people still experience SWB. These theories form the third group of explanation of the construct (genetic theories and personality predisposition) and argue that the subjective well-being experienced is influenced by the stable dispositions of personality.

People's assessments of their subjective well-being reflect cognitive and emotional reactions of vital circumstances. Because circumstances can be short term, can be changed and stable, it is appropriate for investigations to take into account the perception of SWB in the short and long term. This shows that individuals react early to changes in the environment and that these reactions are clear in the momentary experiences of subjective well-being. However, research also showed similar levels of positive affection in different life plans from groups of individuals over extended periods of time, suggesting that people may have stable emotional responses for different life circumstances. From these observations some argue that, although circumstances influence the SWB, people eventually adapt to these changes and return to starting levels or levels of adaptation (Headey, 2008). These adaptation levels or average SWB states are argued as a genetic predisposition of some people toward states of wellness experience. While the environment has been identified as having a role in this measurement, studies in monozygotic and dizygotic twins indicate the existence of biological disposition that influences subject emotional responses, even though the environment is stable and similar among observed subjects (Lykken and Tellegen, 1996). A common practice in psychological research is to make comparative observations of a variable between subjects who have some psychic condition and others who do not. SWB refers to how people experience the quality of their lives, according to the combination of their emotional states-positive and negative affections-and their cognitive judgments. SWB also covers the assessments each person performs on his or her own life, in a context similar to that described by Beck's triad of cognitive schemas, for which it is constituted as a stable construct in time and linked to the subject's personality traits.

\section{Decision Utility and Experienced Utility}

The concept of utility relates to wellbeing as it refers to the benefit that the person derives from a decision or a transaction. The concept of utility is present in the three groups of the satisfaction models exposed. Authors Kahneman and Thaler (2006) distinguish two senses in which the term can be used: the decision utility and experienced utility. The first of these is based on the aforementioned stance of J. Bentham which postulates that people move according to two principles, these being the pleasure and discomfort. Bentham proposes that subjects determine their decisions and actions apart from those two alternatives, trying to get the first and avoid the second. The British philosopher used the word 'utility' to refer to the result this principle of action. Over the years economists and decision theorists have used the term 'utility' with a different meaning than the one originating in Bentham. They refer to the term as the 'wantability' of acquiring a good because of the benefits that will be gained from it. It is an optimization, where 
the object is to maximize that result that will be achieved after deciding and acting. In this way, desirability is inferred from the choices of individuals and used to explain them. Kahneman (2011; Kahneman and Thaler, 2006) call this way of understanding usefulness as decision utility.

In this sense of the concept of utility, is the preferences of the subject based on which he makes the choice consistent with each other and with the axioms of rational decision-making? In contrast to this sense, the authors explain that this sense of decision utility of departs from the idea proposed by Bentham, as the philosopher referred to utility as a hedonic experience, where the individual seeks the well-being or pleasure resulting from the decisions he made. To nominate this distinction, Kahneman and Thaler (2006) introduce the term experienced utility, which maintains the meaning of Bentham's proposal, where what the subject seeks is a hedonic or wellbeing experience that is associated with the satisfactory result he gets from his decisions and actions.

As experienced utility is a post-choice satisfaction, Kahneman and Thaler (2006) propose that when a consumer makes a choice in time to it makes a forecast of the usefulness that they will experience later in $\mathrm{t} 1$. The authors refer to these utility forecasts as hedonic forecasts, and explain that they can be explicit and observable, and implicit, in which case they must be inferred from the choice that the subject makes at the time t0. It can be observed that hedonic forecasts are a prediction of the experienced utility that individuals expect to get because of an election. Authors warn that these hedonic forecasts are not always accurate, meaning that the person can make mistakes when projecting them. To observe this effect, it is possible to measure the hedonic prognosis and compare it with the measure of usefulness experienced by the subject, situation in which the closeness between the two is seen, i.e. whether the expected experience is fulfilled.

Gilovich, Griffen and Kahneman (2002) explain that most hedonic forecasts are made intuitively but not carefully considered, and that in turn forecasts are susceptible to being influenced by biases that are present in other intuitive judgments of the person himself. It is noted that the temporal variable is present in hedonic forecasts, i.e. a decision made in t0 will have effects and differences with consumption made in $\mathrm{t} 1$. The authors consider that the person's mental state and context influences the intuitive assessments that go through their head when they make the choice at the time t0. Thus, they claim that people, while they do know what they want or what they like, cannot always accurately project those they will like when it has a time lapse, thus the prognosis and hedonic experience are influenced by that variable.

Kahneman and Thaler (2006) point to four cases that have been documented where missteps in prognosis and hedonic experience can follow (p.223): (i) when the subject's motivation varies at different times between t0 and $\mathrm{t} 1$; (ii) when the deciding individual focuses its attention on areas of the election's outcome that will not be salient nor relevant to the subsequent experience; (iii) when elections are made based on misguided assessments of experiences; (iv) when people predict their future adjustment to new circumstances in their lives.

The concepts of hedonic prognosis and experienced utility are linked to the notion of subjective well-being (SWB). Since the latter deals with how people experience the quality of their lives, 
according to the combination of their emotional states and cognitive judgments. It is worth noting a symmetry or accordance between the states of subjective well-being and the hedonic forecast that point to the expected usefulness in the decision-making dynamics of the individual.

\section{The stage of consumption and its relationship with consumers' schemas}

Although the literature contains several definitions of satisfaction in consumption, and that there are significant differences in the contents between the definitions of the term, some shared elements are identified. Giese and Cote (2000) recognize three elements: (i) consumer satisfaction is a response with affective, cognitive and conative components; (ii) satisfaction is linked to consumer assessments of product standards, previous consumer experiences and purchasingrelated attributes (e.g. sales service); and (iii) that satisfaction can be expressed at different times, such as before the election, after the election, or after consumption.

According to last element pointed by the authors it may be affirmed that satisfaction is experienced at different stages along the consumption process:

1. When the subject is looking forward to purchasing a good to satisfy a need or for its enjoyment,

2. During the act of purchase,

3. At the time of consumption of the good,

4. After purchasing or consuming the good, as it is an opportunity for the individual to recall the experience of having used the product, satisfied their need or having enjoyed it.

Satisfaction related to the consumption of a good is present in all stages. A consumer can experience satisfaction while in consumption state, as it relates to a product or brand in several manners and stages.

It should be noted that the schemas influence on how each subject relates and value the consumption stage. This is because the mindset and context of each individual (e.g. social, economic and cultural realities) modulate the relevance that a product or service means to the person, and the cognitive or emotional relationship it can maintain with it. The circumstance, valuation and significance of a good, or brand, have distinct nuances in each consumption stage and to each consumer. During consumption stages each persons' schemas act as a framework of perception, meaning and valuation that may lead to the desire and decision of buying a good. When the subject's schemas take part in the consumption's dynamic stages, the schemas influence how information relate to the product is processed. The individual may check if all information is consistent (or not) with his schemas. This is a way to avoid cognitive dissonance during the consumption stages, as the person tries to ensure that there is no divergence between his schema of the product, and its forecasted utility. In the section where cognitive schemas were discussed, some argued schemas are grounded on the meaning that subjects attribute to themselves, their environment and their future. Some argued the schemas are not static, and that they can change depending on the person's perception of its needs, information processing skills, valuation of goods such as branded products, purchasing habits, among others. The consumer's experience during consumption stages may also change over time, as they are shaped over dynamic variables, but always aim to promote the consumer's well-being. This phenomenon may 
be recognized as 'adapted consumption schemas'. An adapted consumption schema responds to the individuals' desire to satisfy a need through the consumption of a product, grounded on his beliefs about himself, the product, and the forecasted satisfaction and subsequent well-being, during any of the consumption stages. Each person's adapted consumption schema allows lasting structures of satisfaction and well-being, as it responds to his beliefs, emotions, behaviors and consumption experiences.

Throughout this work several concepts have been presented: schemas, well-being, satisfaction during consumption stages, and a conceptual combination of the latter entitled adapted consumer schemas. The adapted consumer schemas construes how consumers relate to products, encompassing the dynamic subjective nature of that link. It also provides a useful conceptual framework to analyze other explanations referring to marketing actions and brand messages, aimed at influencing consumer behavior, or their belief systems and attitudes.

\section{References}

Beck, A. T., Rush, A. J., Shaw, B. F., \& Emery, G. (1979). Cognitive therapy of depression, Guilford Press: New York.

Beck, A. T. (1967). Depression: Clinical, experimental, and theoretical aspects. New York: Harper and Row. (Republished as Beck, A.T. \& Alford B.A (2009). Depression: Causes and treatment. Philadelphia:

University of Pennsylvania Press).

Beck, A. T., Freeman, A., Pretzer, J., Davis, D.D., Fleming., B., Ottaviani, T., Beck, J., Simon, K.M., Padesky, D., Meyer, J., \& Trexler, L. (1990). Cognitive Therapy of Personality Disorders. New York: Guilford Press and Associates.

Beck, A. T., Butler, A.C., Brown, G. K., Dahlsgaard, K. K., Newman, C. F., \& Beck, J. S. (2001). Dysfunctional beliefs discriminate personality disorders. Behaviour Research and Therapy, 39(10), 1213-1225.

Brickman \& Campbell (1971). Hedonic relativism and planning the good society. New York: Academic Press. Pp. 287-302.

Csikszentmihalyi, M. (1999). If we are so rich, why aren't we happy? American Psychologist, 54, 821-827.

Csikszentmihalyi, M., \& Csikszentmihalyi, I. (1975). Beyond boredom and anxiety: The experience of play in work and games. San Francisco: Jossey-Bass.

David J.A. Dozois, Aaron T. Beck, Chapter 6 - Cognitive Schemas, Beliefs and Assumptions, In: Keith S. Dobson and David J.A. Dozois, Editor(s), Risk Factors in Depression, Elsevier, San Diego, 2008

Diener, E. (2009). Subjective well-being. In The science of well-being. Springer: Netherlands.

Diener, E., Suh, E. M., Lucas, R. E., \& Smith, H. L. (1999). subjective well-being: Three decades of progress. Psychological Bulletin, 125(2), 276-302. 
Festinger, L. (1962). A theory of cognitive dissonance. New York: Row, Peterson \& Co.

Giese, J. L., \& Cote, J. A. (2000). Defining consumer satisfaction. Academy of Marketing Science Review, 1(1), 1-22.

Gilovich, T., Griffen, D., and Kahneman, D. (2002). Heuristics and Biases: The psychology of intuitive judgement. Cambridge, UK: Cambridge University Press.

Headey, B. (2008). Life goals matter to happiness: A revision of set-point theory. Social Indicators Research, 86(2), 213-231.

Jonas, E., Schulz-Hardt, S., Frey, D., \& Thelen, N. (2001). Confirmation bias in sequential information search after preliminary decisions: An expansion of dissonance theoretical research on selective exposure to information. Journal of Personality and Social Psychology, 80(4), 557-571.

Kahneman, D. (2011). Thinking, fast and slow. Farrar, Straus and Giroux: New York.

Kahneman, D., Diener, E., \& Schwarz, N. (2003). Well-being: The foundations of hedonic psychology. Russell Sage Foundation.

Kahneman, D., \& Thaler, R.H. (2006). Utility Maximization and Experienced Utility. Journal of Economic Perspectives, 20(1), 221-234.

Lykken, D., \& Tellegen, A. (1996). Happiness is a stochastic phenomenon. Psychological Science, 7(3), 186-189.

Maslow, A. H. (1959). A theory of human motivation. Psychological Review. 56, 251-276.

Newman, C. F., Leahy, R. L., Beck, A. T., Reilly-Harrington, N., \& Gyulai, L. (2005). Bipolar disorder: A cognitive therapy approach. Vol. 227. Paidós Editorial.

Paas, F., Renkl, A., \& Sweller, J. (2003). Cognitive load theory and instructional design: Recent developments. Educational Psychologist, 38(1), 1-4.

Pace, T. M. (1988). Schema theory: A framework for research and practice in psychotherapy. Journal of Cognitive Psychotherapy, 2(3), 147-163.

Padesky, C. A. (1994). Schema change processes in cognitive therapy. Clinical Psychology \& Psychotherapy, 1(5), 267-278.

Rummelhart, D.E. (1980). Schema; the building blocks of cognition. In R.J. Spiro, B.C. Bruce and W.F. Brewer (eds) (1980) Theoretical issues in reading comprehension. Hillsdale; N.J. Lawrence Erlbaum Associates

Schmidt, N. B., Joiner, T. E., Young, J. E., \& Telch, M. J. (1995). The Schema Questionnaire: Investigation of psychometric properties and the hierarchical structure of a measure of maladaptive schemas. Cognitive Therapy and Research, 19 (3), 295-321. 
Seligman, M. E. (2011). Flourish: A Visionary New Understanding of Happiness and Well-being. Sheppard L. C., \& Teasdale J.D. (2000). Dysfunctional thinking in major depressive disorder: A deficit in metacognitive monitoring? Journal of Abnormal Psychology, 109, 768 -776. 